\title{
Case History
}

\section{Decimeter-resolution 3D seismic volume in shallow water: A case study in small-object detection}

\author{
Mark E. Vardy ${ }^{1}$, Justin K. Dix ${ }^{1}$, Timothy J. Henstock ${ }^{1}$, Jonathan M. Bull ${ }^{1}$, and Martin Gutowski ${ }^{2}$
}

\begin{abstract}
The 3D chirp subbottom profiler provides high-resolution imaging of coastal and inshore seabed and subseabed structure by combining the known, highly repeatable source waveform of chirp profilers with the coherent processing and interpretation afforded by true 3D seismic volumes. Comprising 60 hydrophone groups arranged around a Maltese cross of four chirp transducers, 3D chirp permits acquisition of a true 3D volume with a horizontal resolution of $12.5 \mathrm{~cm}$, providing an excellent base for shallow-water engineering, archaeological, military, and geologic studies. Here, we present results from surveying an atidal basin on the southern coast of England to map bedrock protrusions and the size and distribution of buried objects. The study area of $150 \times 250 \mathrm{~m}$ provided a series of unique challenges, including a large number of discrete objects ranging from tens of centimeters to several meters in size, buried in a thin veneer (0.5 to $1.5 \mathrm{~m})$ of unconsolidated silt overlaying a flat bedrock surface that showed high acoustic contrast and short wavelength roughness. By comparing comprehensive postsurvey dredging of the entire site with a prestack time-migrated 3D volume, it is possible to confirm a $100 \%$ detection rate for all discrete buried objects larger than $0.30 \times 0.30 \mathrm{~m}$ in an illuminated area, although one acoustic anomaly could not be accounted for in the dredging results.
\end{abstract}

\section{INTRODUCTION}

Detailed (decimetric-scale) imaging of the seabed and subseabed morphology is crucial in the marine construction industry and in homeland defense. Preliminary surveys to identify hazards such as sudden changes in geology or discrete obstructions traditionally combine acoustic seabed mapping and the use of divers with sounding poles. Divers are constrained greatly by environmental conditions such as water temperature, site depth, currents, tides, and particulate suspension levels (visibility). Even in perfect conditions, they can cover only $\sim 10 \mathrm{~m}^{2} /$ day and can sample only the top $1 \mathrm{~m}$ of subsurface. Consequently, there has been much recent work to develop high-frequency surface-scanning acoustics, e.g., side-scan sonar, sector-scanning sonar, and swath bathymetry, for object detection on the seabed (Simms and Albertson, 2000; Quinn et al., 2002). By comparison, there has been limited success in replicating that level of resolution in the subsurface (Schock et al., 2001; Bull et al., 2005).

Chirp or boomer subbottom profilers (operating in the range of 0.4 to $24.0 \mathrm{kHz}$ ) are capable of imaging completely buried structures, but they collapse responses from a 3D environment into 2D vertical slices and therefore provide no cross-dip information. Even after migration, the results are imperfect and confusing sections, commonly degenerated by out-of-plane reflections, especially in areas with rapid structural variations. Because of that and the poor ground coverage afforded by a sparse mesh of 2D lines (with spacing commonly $\geq 10 \mathrm{~m}$ ), they can do little more than indicate zones with a higher risk. However, when chirp or boomer sources are combined with an array of hydrophones, the reflected waveforms can be recorded in 3D (Missiaen, 2005; Scheidhauer et al., 2005), and it is possible to image buried objects, as shown within along-track sections by Schock et al. (2001).

Sampling the reflected waveform in true 3D and with real-time kinematic differential GPS (RTK DGPS) positioning, 3D chirp allows traces to be binned into a geographically oriented grid of 12.5 $\times 12.5 \mathrm{~cm}$, forming a high-resolution 3D seismic volume with dip information for all azimuths and reflections from completely buried

Manuscript received by the Editor 24 April 2007; revised manuscript received 30 July 2007; published online 18 January 2008.

${ }^{1}$ University of Southampton, School of Ocean and Earth Science, Southampton, U. K. E-mail: mev@noc.soton.ac.uk; jkd@noc.soton.ac.uk; then@noc.soton. ac.uk.

${ }^{2}$ GeoAcoustics Ltd, Great Yarmouth, U. K.

(C) 2008 Society of Exploration Geophysicists. All rights reserved. 
structures (Bull et al., 2005). Previous publications have discussed geologic (Bull et al., 2005) and engineering (Gutowski et al., 2007) applications. Here, we present results from a survey acquired in a man-made atidal basin on the southern coast of the United Kingdom, comparing seismic-object identification with comprehensive postsurvey dredging.

\section{METHODOLOGY}

The 3D chirp profiler is a rigid-framed high-resolution subbottom profiler comprising 60 hydrophone groups arranged in a $25-\times 25-$ $\mathrm{cm}$ grid around a Maltese cross of four chirp transducers (Figure 1). Four RTK DGPS antennae provided navigation, giving positioning accurate to $X= \pm 0.46 \mathrm{~cm}, Y= \pm 0.70 \mathrm{~cm}$, and $Z= \pm 1.82 \mathrm{~cm}$ (Bull et al., 2005). The waveforms were recorded at a sampling interval of $0.02 \mathrm{~ms}$ and a horizontal resolution of $12.5 \times 12.5 \mathrm{~cm}$ (Bull et al., 2005). High-resolution chirp subbottom profilers use linear electronics to produce a highly repeatable and tunable swept-frequency acoustic impulse capable of providing centimetric vertical resolution and decametric penetration (Schock and LeBlanc, 1990). That allows the source sweep to be tailored to the specific survey requirements (Gutowski et al., 2002). For this survey, we used a 16-ms-long sweep, scanning linearly from 1.5 to $13.0 \mathrm{kHz}$ with a square envelope. The broader bandwidth than that used for traditional sweeps improves resolution, whereas the short sweep length permits high shot rates of six to eight pulses per second.

Bordered by a harbor wall and caisson, the site was $250 \times 150 \mathrm{~m}$ and was filled in by a thin veneer of fine-grained sediment that overlay a bedrock surface composed of middle or upper Devonian slate. At the time of the survey, obstructions in the northeastern corner and southern quarter restricted the accessible area to $\sim 23,000 \mathrm{~m}^{2}$. However, because the area was closed to all traffic except the survey vessel, sea-state conditions were excellent, and the tight space provided few problems.

The 3D chirp profiler collected more than 20 million traces over two survey days at a tow distance of $5.0 \mathrm{~m}$ behind a small, slowmoving (3 knots) vessel while pulsing six times per second. Acquir-

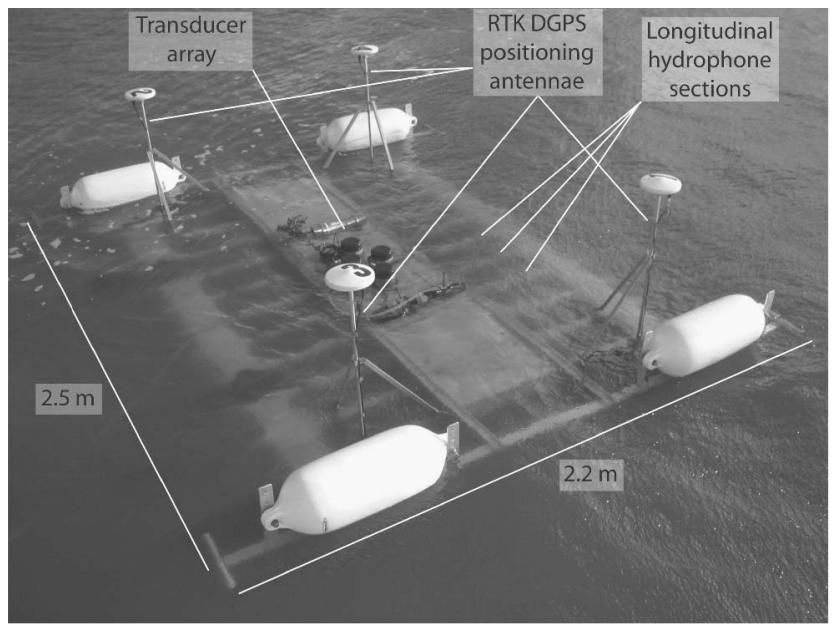

Figure 1. Annotated photograph of a 3D chirp subbottom profiler. The 60 hydrophone groups, housed in 11 longitudinal sections, are arranged in a grid $0.25-\times 0.25-\mathrm{m}$ grid around four central transducers. RTK DGPS positioning of each source-receiver pair permits accurate trace binning onto a $12.5-\times 12.5-\mathrm{cm}$ common-midpoint (CMP) grid. ing lines at $1.0-\mathrm{m}$ line spacing provided $95 \%$ ground coverage with no gaps larger than $3 \times 3 \mathrm{~m}$ and with multiple sampling of each grid bin (Figure 2). The average fold was 15 traces per $12.5-\times 12.5-\mathrm{cm}$ bin, but when the system was temporarily stationary, that rose to $>200$.

We recorded the data in a raw, uncorrelated format, allowing for a later, more flexible processing strategy. We used a simple processing flow to limit the number of potential processing artifacts that might confuse or disrupt reflections from discrete targets of particular interest for this application:

1) Correlation of raw data with the source sweep, reducing all reflections to the Klauder wavelet

2) Cleaning of the data by removing traces with anomalously low signal-to-noise (S/Ns) ratios caused by bubbles in the water column and/or flotsam caught on the system. Using amplitudes extracted from a two-way-traveltime (twt) window centered on the bedrock horizon, we automatically scanned through the volume to remove poor quality traces. Approximately $8 \%$ of the original data volume was removed.

3) Deconvolution using a predictive Wiener filter to remove bedrock ghosting. Although it has been argued that optimum processing of high-resolution chirp data involves a source signature deconvolution (Quinn et al., 1998), we found a simple predictive Wiener filter to be more effective with this source sweep, without damaging the wavelet.

4) Filtering using a band-pass filter (0-1500-13,000-15,000 Hz) to remove unwanted high- and low-frequency noise.

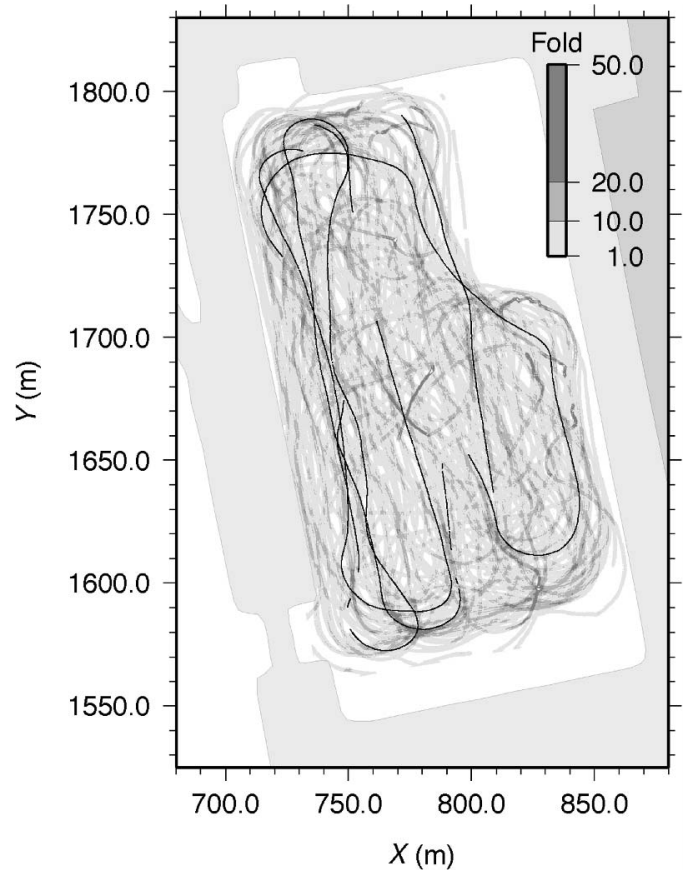

Figure 2. In this plot of fold coverage, darker colors indicate a greater number of traces in the CMP bin. The superimposed black line shows a five-minute subset of GPS locations, highlighting how the acquisition methodology involves strafing an area repeatedly at various sail angles. Gaps in the line are caused by drops in GPS quality, whereas shaded gray areas surrounding acquired volume denote the quayside and a nearby building. Distances in $X$ and $Y$ are projected onto the WGS84 ellipsoid from an arbitrary local zero. 
5) A 3D prestack Kirchhoff time migration implemented by ProMAX was used to move energy back to its correct locations using a velocity of $1400 \mathrm{~m} / \mathrm{s}$, with the lower limit of velocities estimated using diffraction hyperbola curvature. That improved the $\mathrm{S} / \mathrm{N}$ by strengthening the amplitudes of coherent reflectors, and it optimized the resolution to half the receiver spacing (larger than the theoretical limit of $\lambda / 2$ ). Use of the Kirchhoff algorithm also resampled the irregularly positioned data onto a regular volume. Given the limited source-receiver offsets of the array and the small thickness of the objects relative to the source wavelength, the migration algorithm has a low sensitivity to small-scale fluctuations in the velocity model. Therefore, we made no attempt to account for the objects within the velocity model; rather, a homogeneous velocity was preferred, even when migrating small cubes that included clearly identifiable targets.

Traditional processing of chirp subbottom profiler data involves applying an envelope function as the last processing stage. That removes all phase and polarity information and can cause some vertical smearing, but it improves $\mathrm{S} / \mathrm{N}$, especially for weaker horizons. Given the naturally high $\mathrm{S} / \mathrm{N}$ of these data (Figure 3 ), we chose not to apply the envelope function. This representation of results in their true form and polarity provides useful discrimination between degraded and nondegraded reflecting objects.

\section{SEABED AND BEDROCK STRUCTURE}

\section{Data quality and gross structure}

Within the chirp seismic volume, two continuous reflection horizons that extend across the entire survey area are clearly distinguishable (Figure 3). Because the envelope function has not been applied to those data, the seabed and bedrock horizons appear as classic Klauder wavelets with positive (black) side lobes flanking a negative (white) central peak. The shallowest reflection is the seabed (twt ca. $12.6 \mathrm{~ms}$ ), which is relatively weak, whereas the deeper slate interface (twt ca. $13.2 \mathrm{~ms}$ ) is a relatively high-amplitude reflection.

Using a sound velocity of $1500 \mathrm{~m} / \mathrm{s}$, the higher-amplitude, deeper horizon sits at an average depth of $\sim 10.4$ m below the local datum (defined as the height of the local base station, which is +55.559 m from the WGS84 geoid) and demonstrates little topography (Figure 4a). Except for two discrete depressions (of which only the western one is imaged completely), the bedrock surface varies $<0.1 \mathrm{~ms}(<0.07 \mathrm{~m})$, forming a gentle north-south gradient of $<0.2^{\circ}$.

Across $86 \%$ of the volume, the bedrock surface is easily identifiable, but in four zones (I through IV, Figure 4a), the bedrock horizon becomes discontinuous and confused. In zones I and II, highamplitude returns from an overlying morass of superimposed diffraction hyperbolae mask re- sponse from the deeper bedrock (Figure $5 \mathrm{c}$ and d). Subsequent dredging identified those as piles of waste material (e.g., rope, wire, cables, wood, and tires) dumped along the basin margin. Similarly, the bedrock is masked in zones III and IV by an irregular, reverse-polarity horizon 10 to $15 \mathrm{~cm}$ above the average bedrock surface (Figure $5 \mathrm{a}$ and $\mathrm{b}$ ).

The area covered by the latter horizon is $1225 \mathrm{~m}^{2}$, the largest zone of which (III) has a maximum extent of $65 \mathrm{~m}$ from north to south and $25 \mathrm{~m}$ from east to west (Figure 5a and b). The horizon's asymmetry with seabed topography makes it unlikely to be shallow gas. Given the low density and thin covering of overbearing sediments, it is difficult to correlate it with a possible source/trap. Similar acoustic signatures have been observed in archaeological sites, where they commonly have been associated with low-density material such as wood/rope and peat layers (Quinn et al., 1997a; Quinn et al., 1997b; Arnott et al., 2005; Plets et al., 2007). However, the postsurvey dredging failed to identify any material. The high amplitudes sug-

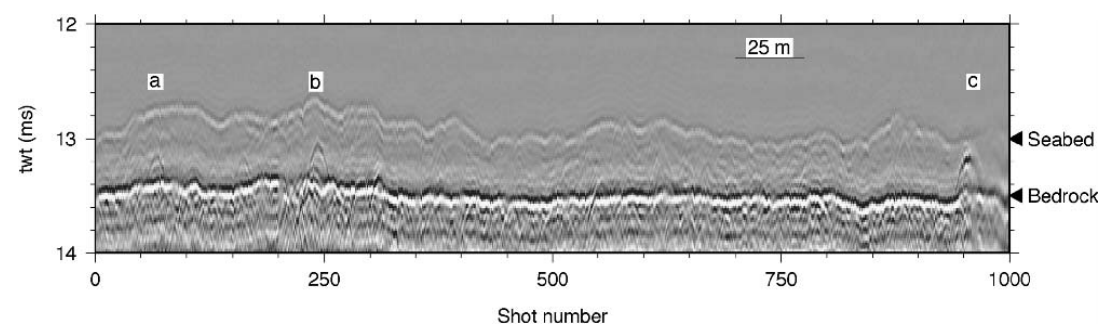

Figure 3. Data recorded using channel 23 for an arbitrary section of 1000 shots. Using no processing other than a standard correlation to collapse the swept-frequency waveform back to a Klauder wavelet, the seabed and bedrock appear as clean, crisp horizons, and three diffraction hyperbolae (labeled a, b, and c) are clearly visible in the sediment cover.
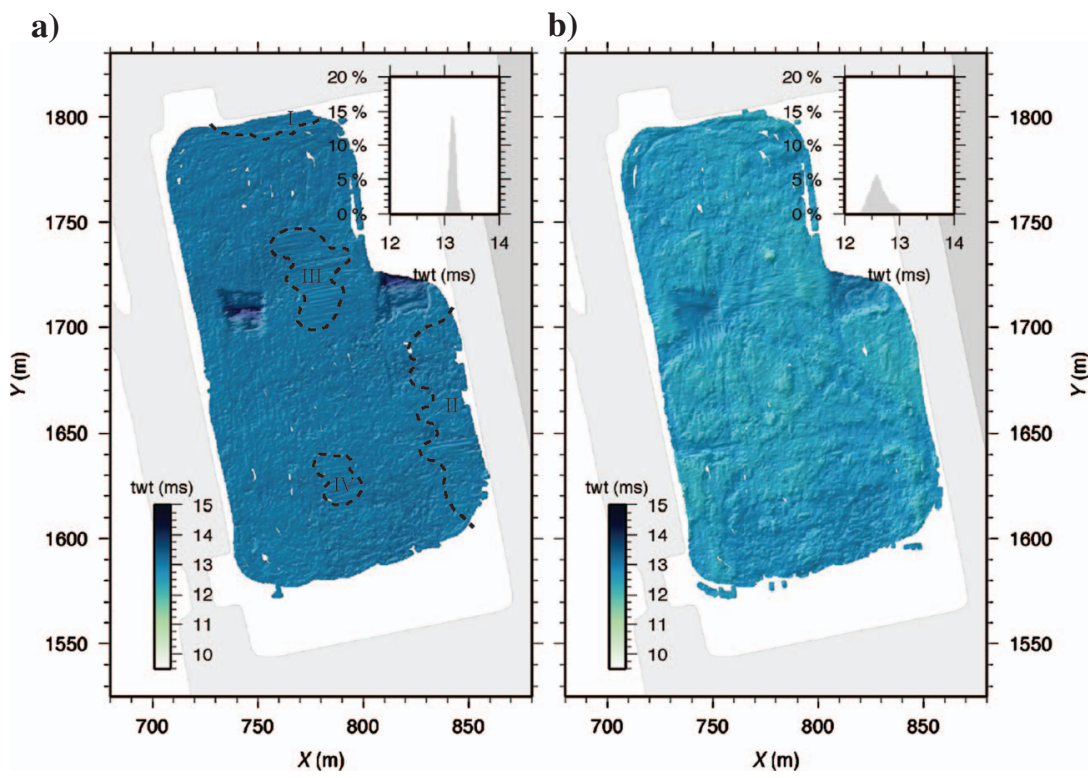

Figure 4. Surface maps show two-way traveltime (twt) to (a) bedrock and (b) seabed, horizons displayed using the same color scale. Insets show histograms of surface twt, highlighting the lack of topography, particularly on the bedrock horizon, where $98 \%$ of returns arrive in a 0.3 -ms twt window. Outlined areas I through IV are zones of discontinuous bedrock reflections (see text for details). 
gest that if the horizon is the result of an accumulation of degraded material, it will be degraded heavily, making it probable that the material would have disintegrated in the dredge head.

The weaker, shallower horizon sits at an average depth of $\sim 9.1 \mathrm{~m}$ and is consistent with the seabed of unconsolidated, fine-grained sediments described by preliminary diver sorties. Unlike the bedrock, the seabed displays a more irregular topography (Figure 4b), causing the sediment cover to be highly variable (Figure 6). The average thickness of the sediment cover is $0.76 \mathrm{~ms}$ twt $(\sim 0.6 \mathrm{~m})$, but it thins to $<0.2 \mathrm{~ms}$ twt $(<0.15 \mathrm{~m})$ in the west and south and thickens to $1.96 \mathrm{~ms}$ twt $(\sim 1.5 \mathrm{~m})$ in the two depressions.

The lack of sediment infill to the south and the presence of partially eroded, relic dredging scour marks is consistent with recorded dredging in the 1980s and 1990s. Other than two discrete depressions, where the sediment thickening is caused by infilling of bedrock anomalies, several smaller, individual seabed promontories rise to $0.50 \mathrm{~m}$ above the average bed depth. In most cases, those take the form of large diffraction hyperbola (or collections thereof) that protrude into the water column and can be as much as $7.0 \mathrm{~m}$ in diameter. Dredging confirmed them to be piles of dumped material, commonly tangled conglomerates of rope, wire, hose, and broken chunks of wood. Similarly, to the north and east there are seabed highs, $\sim 0.25 \mathrm{~m}$ above average depth, that are coincident with the areas where dumped material obscures bedrock returns.

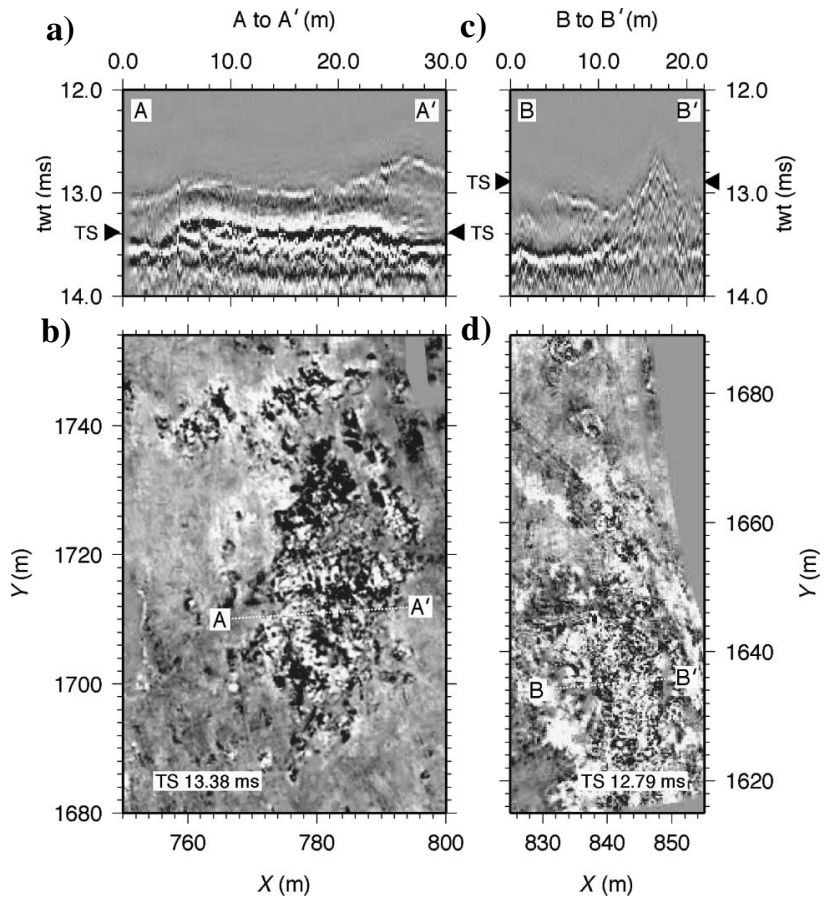

Figure 5. (a) Vertical section and (b) time slice through lower sediments, $\sim 0.10 \mathrm{~m}$ above the bedrock horizon, of the largest reversepolarity anomalies. With a maximum extent of $65 \mathrm{~m}$ from north to south and $25 \mathrm{~m}$ from east to west, this horizon covers $915 \mathrm{~m}^{2}$ and displays a broken upper surface with considerably more topography than the overlying seabed. (c) Vertical section and (d) time slice through the zone II anomaly that runs parallel to the eastern boundary of the basin.

\section{Seabed and bedrock depressions}

Two anomalous seabed and bedrock depressions measuring $\sim 20 \mathrm{~m}$ in diameter and $2 \mathrm{~ms}$ twt (ca. $1.5 \mathrm{~m}$ ) below the average bedrock level at their deepest points are observed centered at $X=740$, $Y=1710$ and $X=815, Y=1720$. (Figure 7 shows sections and slices through the western depression.) The structures appear to be defined morphologically by the bedrock, with sediment infill mimicking the underlying structure.

The western depression, the only one we have complete coverage of, measures $20 \mathrm{~m}$ from east to west and $18 \mathrm{~m}$ from north to south. The sides are steepest to the east and west, dipping at $19^{\circ}$ and $20^{\circ}$ angles from horizontal, respectively (Figure $7 \mathrm{a}$ and $\mathrm{b}$ ). The southern slope is much shallower, $6^{\circ}$, whereas the northern slope is stepped (Figure $7 \mathrm{a}$ ). The upper wall slopes down at a $17^{\circ}$ angle from the horizontal before flattening out into a 5.0-m-wide ledge (Figure $7 \mathrm{a}$ and b). The lower section slopes down at a $14^{\circ}$ angle and terminates against the opposite, southern slope, forming the base of the depression.

The steep eastern and western boundaries lead to the formation of a linear pit floor that stretches $15 \mathrm{~m}$ at an orientation of $113^{\circ}$ from northwest to southeast (Figure 7f) and appears to be a sharp intersection of the dipping northern and southern slopes, with little or no shallowing (Figure 7a and b).

There is no historical evidence for excavation of two such structures, either as part of the most recent basin developments in the 1950s or before that. However, World War II air-raid warden records note the impact of a large number of high-explosive and incendiary

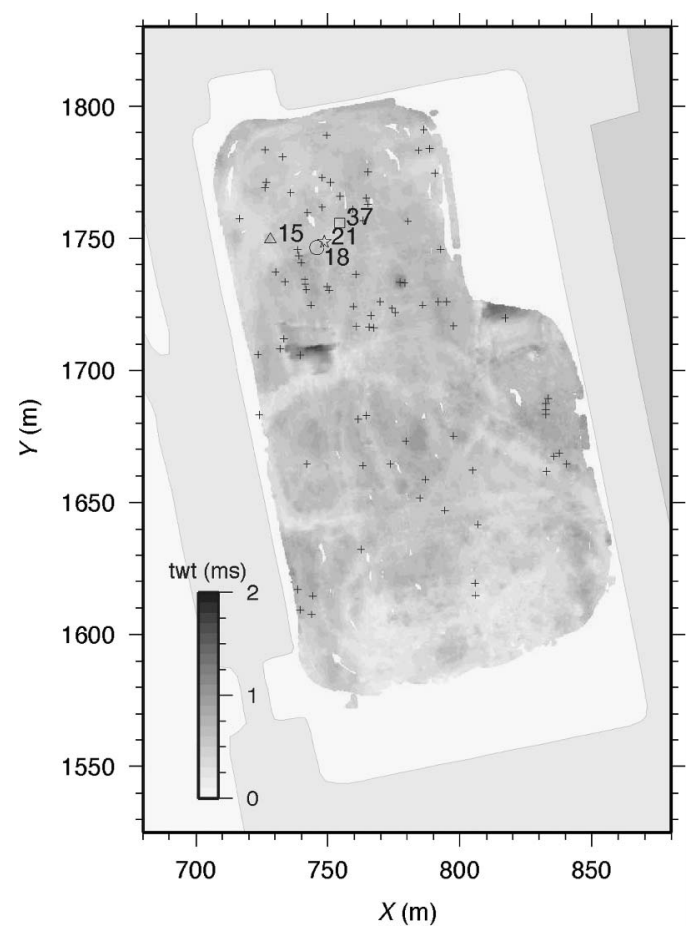

Figure 6. In this sediment isopach map (two-way traveltime), crosses mark locations of acoustically identified buried targets. The three objects used as examples for comparing seismic and dredging results are identified by acoustic target numbers $(15,18$, and 37$)$ and by a triangle, circle, and square, respectively. Similarly, target 21, used to highlight the advantages of using unmigrated volumes in Figure 8, is identified by a star. 
shells that fell in the vicinity of the surveyed area, and local records support the possibility of those being bomb craters. That would agree with time slices through the lower sediments, which show dramatically increased returns in areas surrounding the craters that might be indicative of ejected material (Figure 7c). It is not immediately obvious why the depressions are so distinctly square in cross section, although it seems likely to be linked to the slate bedrock deforming along preexisting cleavage planes.

\section{SMALL-OBJECT IDENTIFICATION}

\section{Seismic characteristics}

The survey was undertaken to map bedrock structures above the seabed and/or the size and distribution of buried and partly buried objects before targeted dredging. During interpretation of the 3D seismic volume, a set of criteria was used to identify suitable targets for the subsequent dredging - a "target" being a reflection event
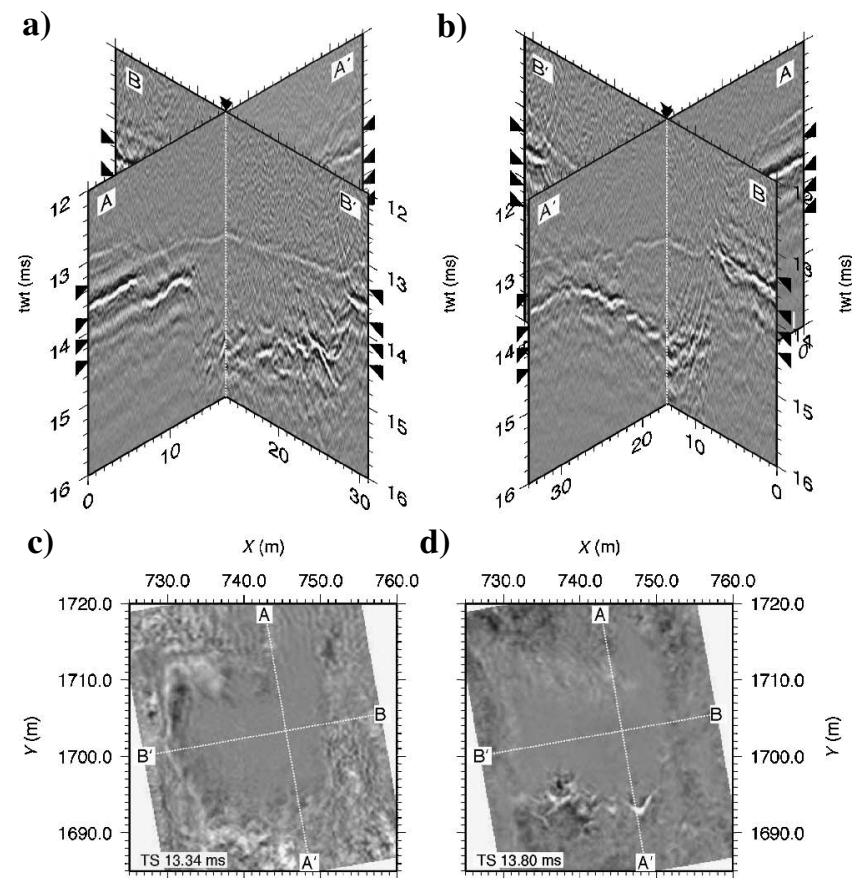

d)

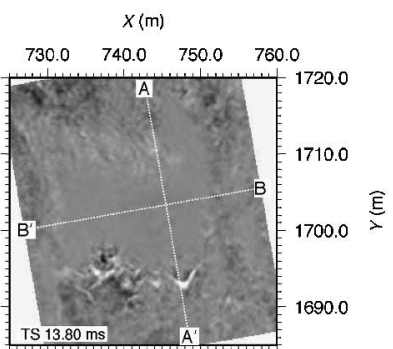

e)

f)
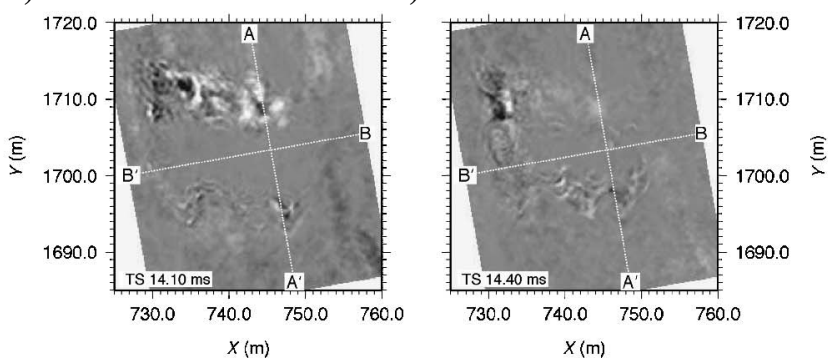

Figure 7. Fence diagrams of vertical sections looking from (a) northwest and (b) southeast, with (c-f) sequence of time slices moving down through the western bedrock depression. (c) Slices through the lower sediments, $0.15 \mathrm{~ms}$ above the bedrock surface, show strong, discontinuous reflections, possibly from ejected debris. Panels (d) through (f) show the changing shape of the crater with increasing depth, forming a narrow, $15-\mathrm{m}$-long pit floor oriented along a $113^{\circ}$ angle. that exhibits the distinctive diffraction hyperbolas associated with a localized acoustic impedance contrast. Using that methodology, 89 individual seismic targets (black crosses, Figure 6) were found in the survey area. Concentrated mainly in the northern half of the basin, some targets appear to be clustered, e.g., the seven that form a line parallel to the basin margin, $29 \mathrm{~m}$ in from the western wall, starting at $X=746, Y=1725$ and moving northward. The targets in the basin range from 0.09 to $38.5 \mathrm{~m}^{2}$ in the migrated illuminated area, both protrude from the seabed and are buried completely, and demonstrate reverse and normal polarities.

Identifying the objects in a migrated volume is extremely difficult because the reflection covers very few CMP bins, the smallest being a square 3 bins $\times 3$ bins. In contrast, locating them in unmigrated data is considerably easier because their associated diffraction hyperbolas can be as much as $7.0 \mathrm{~m}$ in diameter. Figure 8 shows a series of time slices moving down through the hyperbola of acoustic target 21 in $0.02-\mathrm{ms}$ twt steps. The migrated horizon (final time slice, Figure 8) covers $<1.5 \mathrm{~m}^{2}$, or $<9$ pixels square, whereas the hyperbola has opened out to form an easily identifiable 3.0-m-diameter ring $0.16 \mathrm{~ms}$ twt $(\sim 0.11 \mathrm{~m})$ below the object. This coherent opening of the diffraction hyperbolas into distinctive ringed structures provided us with a method to quickly and effectively identify all objects buried in the basin.

Once each target had been located, we migrated small, 25-m square cubes centered on each object. From this geometrically correct horizon, it was possible to extract estimates of object dimensions, along with polarity information that might indicate the material nature of the object.

\section{Comparison of acoustic targets with dredging results}

After completion of the 3D chirp seismic survey, a comprehensive dredging program was undertaken to retrieve all discrete small ob-

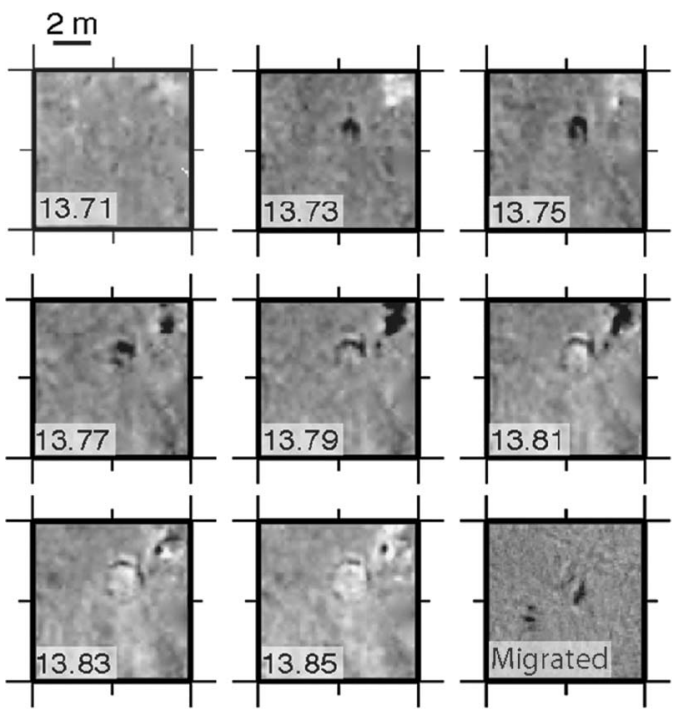

Figure 8 . Panels show $10-\times 10$-m time slices that begin just above and move down through diffraction hyperbola of seismic target 21 in steps of $0.02 \mathrm{~ms}$. The peak of the hyperboloid, although high in amplitude, is small, $\sim 1 \mathrm{~m}^{2}$, whereas $0.16 \mathrm{~ms}$ lower, it opens out into a $3.0-\mathrm{m}$ diameter ring. By cycling up and down through the $3 \mathrm{D}$ volume, we easily could identify buried targets through their coherent diffraction hyperboloids. In comparison, the migrated horizon, the final time slice, is harder to identify as a "real" target, being $<1.5$ square $\mathrm{m}^{2}$ in size and extending over approximately four time slices. 
jects. A 0.66- $\mathrm{m}^{3}$ bucket dredge was deployed from a four-legged dredging platform $30 \times 15 \mathrm{~m}$, with a separate, free-floating pontoon-mounted hopper for sieving. Positioning a DGPS antenna over the pivot point allowed each grab to be located to an accuracy of $\pm 2.0 \mathrm{~m}$. However, the use of a bucket grab prevented the acquisition of any orientation information or burial depth.
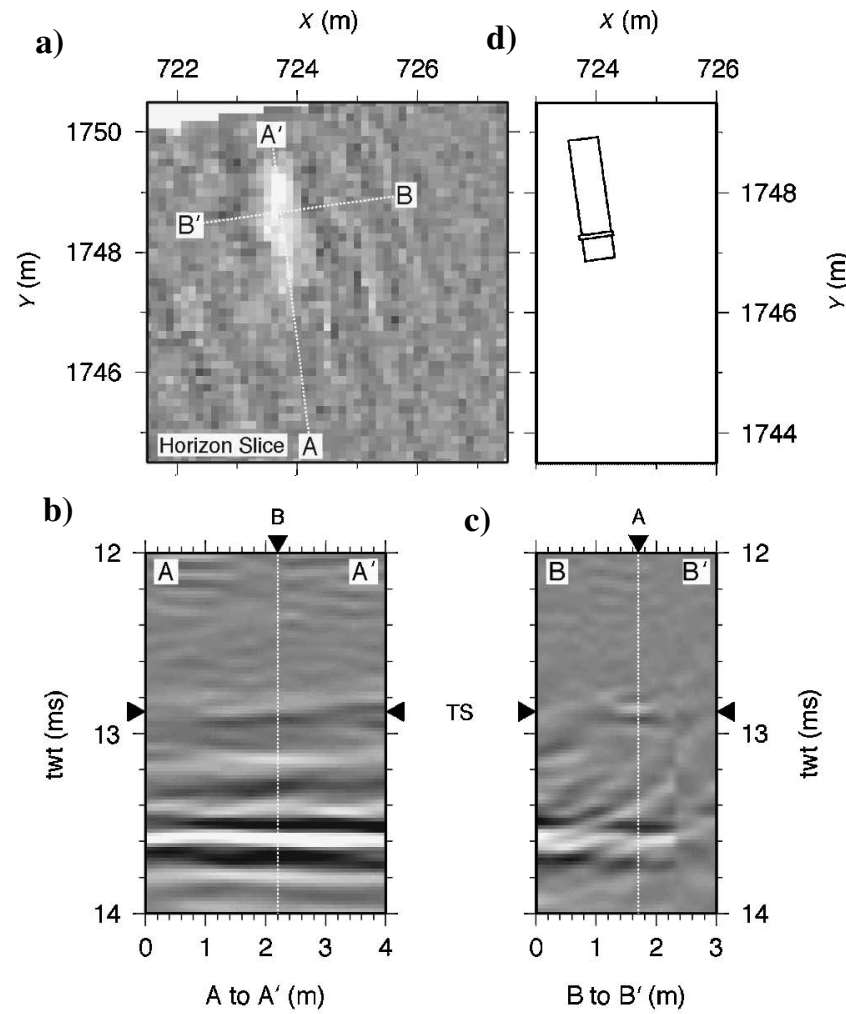

e)

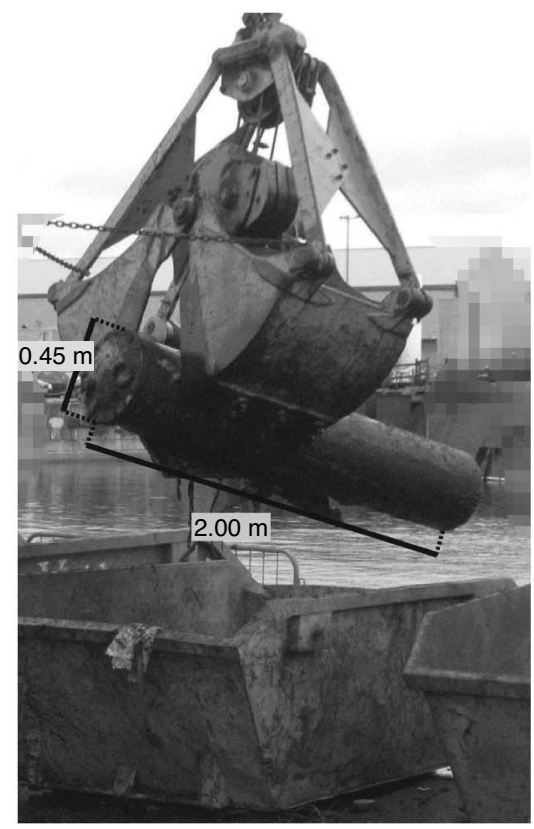

Figure 9. (a) Horizon slice, (b) vertical slice along axis, and (c) vertical slice across the axis through the migrated volume centered on acoustic target 15. (d) Location map and (e) photo of the object dredged from this site, a metal cylinder $2.0 \times 0.45 \mathrm{~m}$ in diameter. Vertical exaggeration is $4: 1$.
Because of possible further development of the basin, it was important that all objects be cleared, so dredging was not guided onto specific seismic targets. Instead, the entire $23,000-\mathrm{m}^{2}$ area was cleared systematically, making possible an exhaustive comparison of acoustically identified targets with dredged objects.

All objects recovered during dredging correlated to a coincident acoustic target, and for every target identified during the seismic survey, an object of appropriate dimensions was retrieved. To illustrate that agreement between acoustic and dredging results, we will consider three examples, seismic targets 15, 18, and 37 (Figure 6).

\section{Target 15}

In the migrated volume, target 15 forms a long (2.0-m), narrow (0.3-m) normal-polarity reflection event (Figure 9). Sitting at a depth of $12.90 \mathrm{~ms}$ twt, $\sim 0.50 \mathrm{~m}$ above the bedrock horizon, it is contiguous with the seabed and slopes slightly from north to south at a $2^{\circ}$ angle from horizontal.

A large, metal cylinder $2.0 \mathrm{~m}$ long and $0.45 \mathrm{~m}$ in diameter was recovered from this location (Figure $9 \mathrm{~d}$ and e). A closer inspection showed that the cylinder's seals had remained intact, there were no significant accumulations of rust, and the object appeared to be filled with air and empty of liquid. Although the dimensions of the acoustic event are an excellent match for those of the recovered object, the reflection is surprisingly low in amplitude for a target that presents such a large impedance boundary.

\section{Target 18}

Acoustic target 18 is a reverse-polarity event $3.8 \times 0.75 \mathrm{~m}$ that sits at an average depth of $13.22 \mathrm{~ms}$ twt $(\sim 9.3 \mathrm{~m})$. As with target 15 , it is not flat; rather, it dips from south to north at a $0.5^{\circ}$ angle from horizontal. The vertical sections (Figure $10 \mathrm{~b}$ and c) provide a better indication of the size and shape of the migrated horizon, and its reversed polarity suggests that it is a wooden object, probably degraded (Quinn et al., 1997a; Quinn et al., 1997b; Arnott et al., 2005; Plets et al., 2007).

At this location, a wooden railway sleeper $4.0 \times 0.36 \times 0.08 \mathrm{~m}$ was found (Figure 10d and e). Heavily degraded, the sleeper broke apart when it landed in the hopper and again when transferred to a skip. This object is a good match in size and composition for the observed acoustic target.

\section{Target 37}

Target 37 is an anomalously shaped, 1.8-m long, high-amplitude reflection event. For most of its length, it is $0.5 \mathrm{~m}$ wide, but it broadens to $1.0 \mathrm{~m}$ to the south. The peak of the Klauder wavelet is $0.25 \mathrm{~ms}$ twt $(\sim 0.18 \mathrm{~m})$, above that of the bedrock, and runs parallel along a shallow south-to-north gradient of $0.5^{\circ}$ from the horizontal. Similar to target 18 , it is reverse polarity, which we would expect to indicate an object composed of wood, probably degraded.

The object found here was a wooden pole $0.10 \times 0.13 \times 1.80 \mathrm{~m}$, attached at one end to a U-shaped metal plate $0.40 \times 0.30 \mathrm{~m}$, with 0.02-m-high sides (Figure 11d and e). Closer inspection showed that the wooden bar was degraded badly, with large chunks being broken off easily. Interestingly, at no point does the acoustic event revert to normal polarity, even though the shape and dimensions (Figure 11a) agree extremely well with the retrieved object. 


\section{DISCUSSION}

The results demonstrate an excellent correlation between the observed seismic reflection event and the recovered object. A key factor in achieving that is the processing of data. For example, in the unmigrated volume surrounding target 18 , the horizon disappears into a data gap to the south, meaning that the peak of the diffraction hyperbola is only $\sim 2.5 \mathrm{~m}$ long. Postmigration, the hyperbola has been

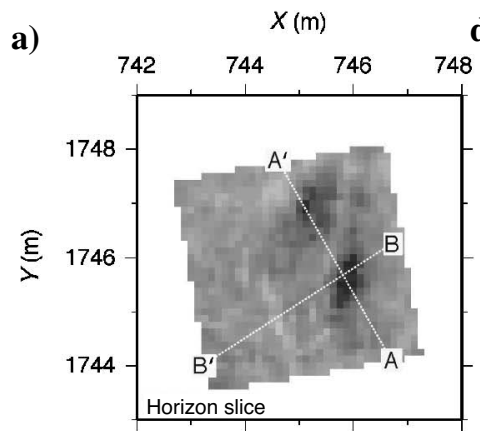

d) $\quad X(m)$ b)

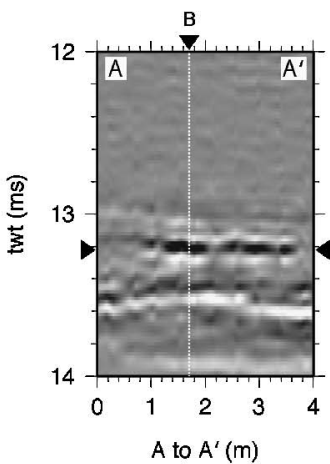

c)

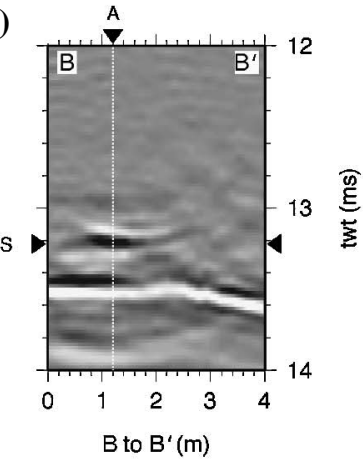

e)

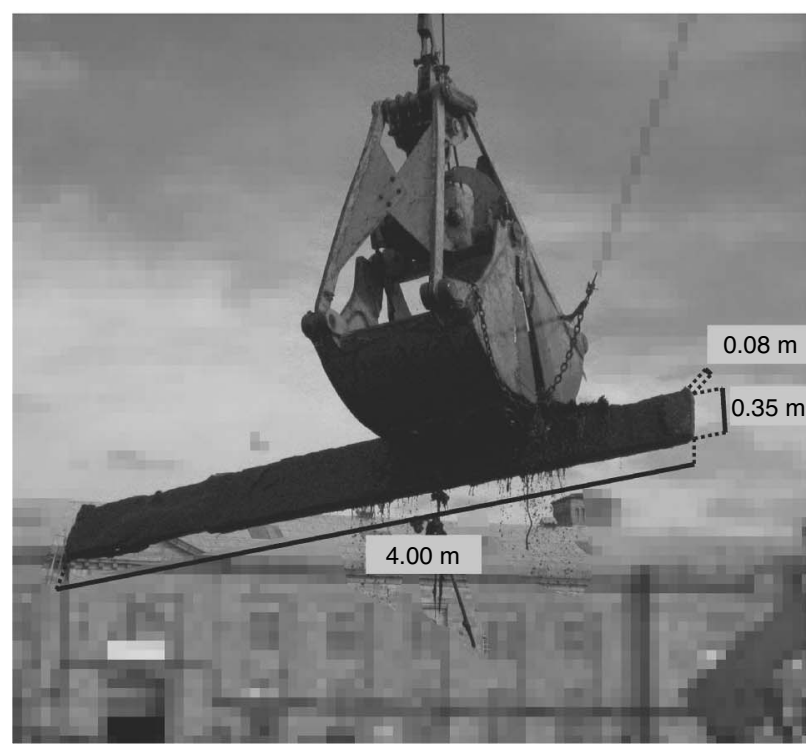

Figure 10. (a) Horizon slice and (b-c) vertical slices through acoustic target 18. (d) Location map and (e) photo of the object recovered, a heavily degraded wooden railway sleeper measuring $4.0 \times 0.35$ $\times 0.08 \mathrm{~m}$. Vertical exaggeration is $4: 1$. collapsed back to a reflection event of similar length to the coincident object, highlighting the advantage of using a 3D Kirchhoff migration to resample the data onto a regular grid.

The amplitudes of the seismic reflections, migrated or otherwise, cannot be taken simply as a proxy for material properties of the object. The dimensions of the targets cause waveforms from upper and lower surfaces to interfere. As Widess (1973) discusses, when thinking in terms of thin beds in multichannel seismic data, this can dramatically reduce the amplitude and alter the shape of the reflected wavelet. The anomalous amplitude of target 15 therefore is likely to be a result of the thickness of the metal sheeting being substantially less than the dominant wavelength.
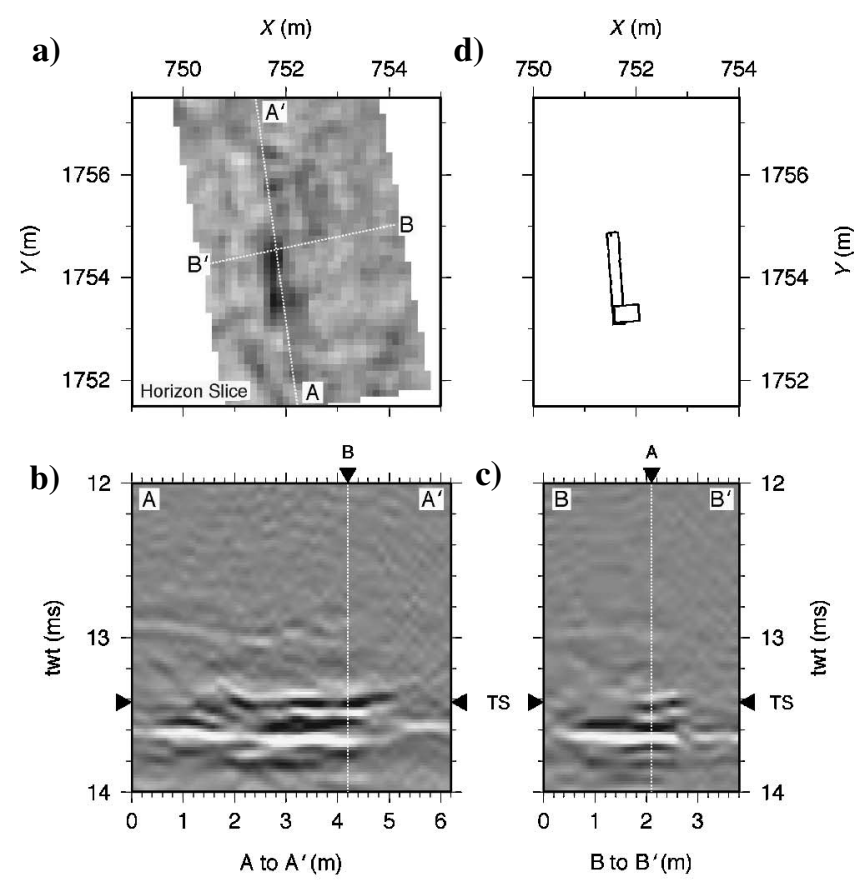

e)

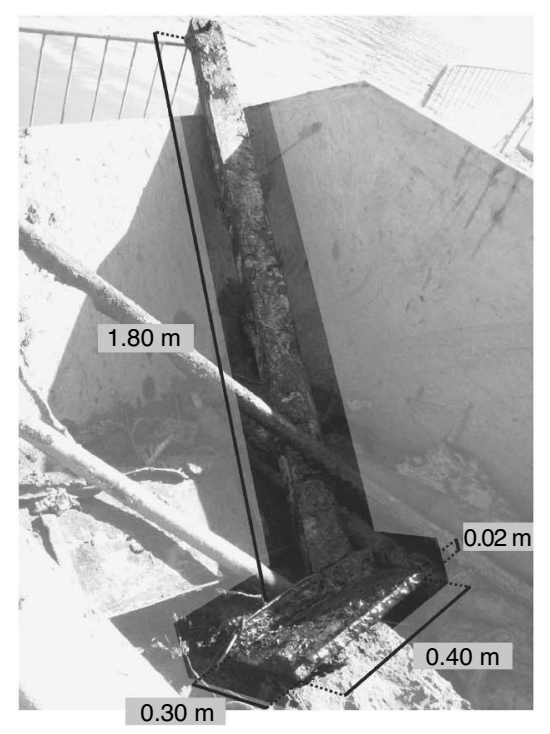

Figure 11. (a) Horizon slice and (b-c) vertical slices through acoustic target 37. (d) Location map and (e) photo of the wooden pole (1.80 $\times 0.13 \times 0.10 \mathrm{~m})$ and attached metal sheet $(0.40 \times 0.30 \mathrm{~m})$ found during dredging. Vertical exaggeration is $4: 1$. 
Similarly, for target 37 , because the plate is attached to the pole, the two would not be resolvable into two distinct sources, making the resultant reflection event a combined response from both. Because the metal plate is $<0.01 \mathrm{~m}$ thick, the acoustic response will suffer from destructive interference in the same manner as the metal cylinder found at the site of target 15 , leading to the reflection being dominated by the response from the wooden pole. That agrees with the reflection event becoming lower amplitude to the south.

\section{CONCLUSIONS}

We presented the results of a survey in an atidal basin on the southern coast of the United Kingdom using the 3D chirp high-resolution subbottom profiler. The data permitted detailed mapping of seabed and bedrock structure in 3D and the acoustic identification of 89 discrete buried targets. Except for the acoustic anomaly labeled as zones II and IV, subsequent postsurvey dredging confirmed a 100\% success rate in identifying buried objects and showed a strong correlation between observed acoustic signature and object size.

With those results, we successfully demonstrated that through acquisition of a high-resolution 3D seismic volume with decimetric horizontal resolution and centimetric vertical resolution, it is possible to locate buried objects presenting an acoustically illuminated surface larger than $0.30 \times 0.30 \mathrm{~m}$. Indeed, through interpretation of a 3D migrated volume, it is possible to estimate the approximate size and shape of objects and in some cases to determine the nature of the buried material.

\section{ACKNOWLEDGMENTS}

The authors wish to thank the MoD (SaMO), the Engineering and Physical Sciences Research Council/Joint Grant Scheme (GR/R 12695/01), and GeoAcoustics Ltd. for their help in developing the system. The authors would also like to acknowledge the reviewers for their encouraging and constructive comments, along with Simon Dean and Ruth Plets for their technical expertise and Luke Pinson,
Ray Collins, John Davis, and Bob Wilkie for their practical assistance.

\section{REFERENCES}

Arnott, S. H. L., J. K. Dix, A. I. Best, and D. J. Gregory, 2005, Imaging of buried archaeological materials: The reflection properties of archaeological wood: Marine Geophysical Researches, 26, 135-144.

Bull, J. M., M. Gutowski, J. K. Dix, T. J. Henstock, P. Hogarth, T. G. Leighton, and P. R. White, 2005, Design of a 3D chirp sub-bottom imaging system: Marine Geophysical Researches, 26, 157-169.

Gutowski, M., J. Bull, J. Dix, T. Henstock, P. Hogarth, T. Leighton, and P. White, 2002, Chirp sub-bottom profiler source signature design and field testing: Marine Geophysical Researches, 23, 481-492.

Gutowski, M., J. M. Bull, J. K. Dix, T. J. Henstock, P. Hogarth, T. Hiller, T. G Leighton, and P. R. White, 2007, 3D high-resolution acoustic imaging of the sub-seabed: Journal of Applied Acoustics, doi:10.1016/j.apacoust.2006.08.010.

Missiaen, T., 2005, VHR marine 3D seismics for shallow water investigations: Some practical guidelines: Marine Geophysical Researches, 26, $145-155$

Plets, R. M. K., J. K. Dix, J. R. Adams, and A. I. Best, 2007, 3D Reconstruction of a shallow archaeological site from high-resolution acoustic imagery: The Grace Dieu: Journal of Applied Acoustics, doi:10.1016/j.apacoust.2007.04.004

Quinn, R., J. M. Bull, and J. K. Dix, 1997a, Imaging wooden artefacts using chirp sources: Archaeological Prospection, 4, 25-35.

Quinn, R., J. M. Bull, and J. K. Dix, 1998, Optimal processing of marine high-resolution seismic reflection (chirp) data: Marine Geophysical Researches, 20, 13-20.

Quinn, R., J. M. Bull, J. K. Dix, and J. R. Adams, 1997b, The Mary Rose site - Geophysical evidence for paleo-scour marks: The International Journal of Nautical Archaeology, 26, 3-16.

Quinn, R., W. Forsythe, C. Breen, M. Dean, M. Lawrence, and S. Liscoe, 2002, Comparison of the Maritime Sites and Monuments Record with side-scan sonar and diver surveys: A case study from Rathlin Island, Ireland: Geoarchaeology: An International Journal, 17, 441-451.

Scheidhauer, M., F. Marillier, and P. Thierry, 2005, Detailed 3D seismic imaging of a fault zone beneath Lake Geneva, Switzerland: Basin Research, 17, 155-169.

Schock, S. G., and L. R. LeBlanc, 1990, Chirp sonar: New technology for sub-bottom profiling: Sea Technology, 31, 35-43.

Schock, S. G., A. Tellier, J. Wulf, J. Sara, and M. Ericksen, 2001, Buried object scanning sonar: IEEE Journal of Ocean Engineering, 26, 677-689.

Simms, J. E., and P. E. Albertson, 2000, Multidisciplined investigation to locate the Kentucky shipwreck: Geoarchaeology: An International Journal, 15, 441-468.

Widess, M. B., 1973, How thin is a thin bed?: Geophysics, 38, 1176-1180. 